National Institute of

Standards and Technology

U.S. Department of Commerce

\title{
Specification for Asset Identification 1.1
}

John Wunder

Adam Halbardier

David Waltermire 


\author{
John Wunder \\ Adam Halbardier \\ David Waltermire
}

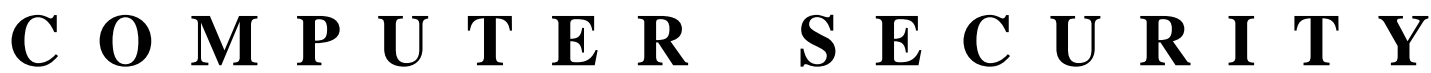

Computer Security Division

Information Technology Laboratory

National Institute of Standards and Technology

Gaithersburg, MD 20899-8930

June 2011

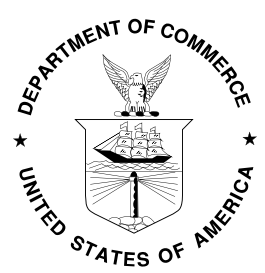

U.S. Department of Commerce

Gary Locke, Secretary

National Institute of Standards and Technology

Dr. Patrick D. Gallagher, Director 


\section{Reports on Computer Systems Technology}

The Information Technology Laboratory (ITL) at the National Institute of Standards and Technology (NIST) promotes the U.S. economy and public welfare by providing technical leadership for the nation's measurement and standards infrastructure. ITL develops tests, test methods, reference data, proof of concept implementations, and technical analysis to advance the development and productive use of information technology. ITL's responsibilities include the development of technical, physical, administrative, and management standards and guidelines for the cost-effective security and privacy of sensitive unclassified information in Federal computer systems. This Interagency Report discusses ITL's research, guidance, and outreach efforts in computer security and its collaborative activities with industry, government, and academic organizations.

\section{National Institute of Standards and Technology Interagency Report 7693 36 pages (June 2011)}

\footnotetext{
Certain commercial entities, equipment, or materials may be identified in this document in order to describe an experimental procedure or concept adequately. Such identification is not intended to imply recommendation or endorsement by the National Institute of Standards and Technology, nor is it intended to imply that the entities, materials, or equipment are necessarily the best available for the purpose.
} 


\title{
Acknowledgments
}

The authors, John Wunder of The MITRE Corporation, Adam Halbardier of Booz Allen Hamilton, and David Waltermire of the National Institute of Standards and Technology (NIST) wish to thank their colleagues who reviewed drafts of this document and contributed to its technical content. The authors would like to acknowledge Paul Cichonski and Harold Booth of NIST, Karen Scarfone of Scarfone Cybersecurity, Joseph Wolfkiel of the Defense Information Systems Agency (DISA), Jim Ronayne of Varen Technologies, Gary Newman of Belarc, Gerard McGuire of The MITRE Corporation, and Mark Johnson of Booz Allen Hamilton for their keen and insightful assistance throughout the development of the document.

\begin{abstract}
Asset identification plays an important role in an organization's ability to quickly correlate different sets of information about assets. This specification provides the necessary constructs to uniquely identify assets based on known identifiers and/or known information about the assets. This specification describes the purpose of asset identification, a data model for identifying assets, methods for identifying assets, and guidance on how to use asset identification. It also identifies a number of known use cases for asset identification.
\end{abstract}

\section{Trademark Information}

CPE is a trademark of The MITRE Corporation.

All other registered trademarks or trademarks belong to their respective organizations. 


\section{Table of Contents}

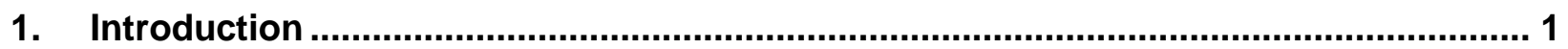

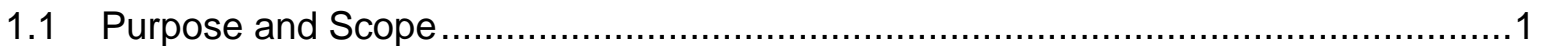

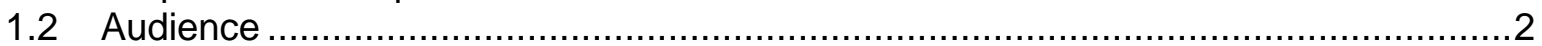

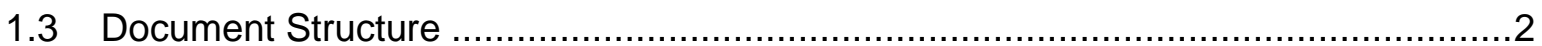

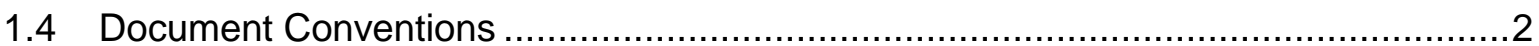

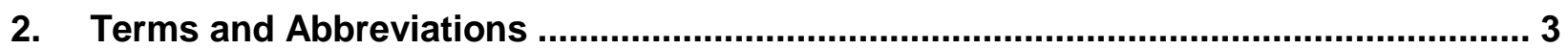

2.1 Terms

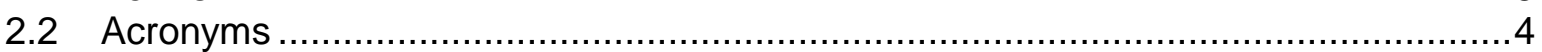

3. Relationship to Existing Standards and Specifications ........................................... 5

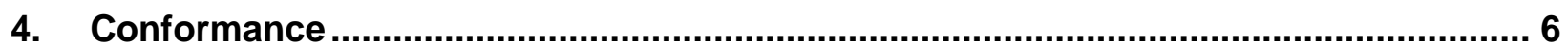

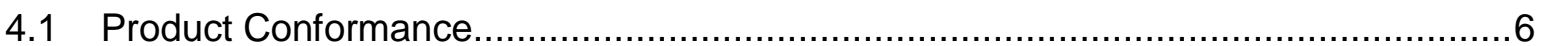

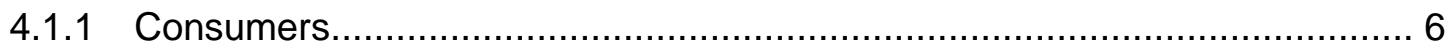

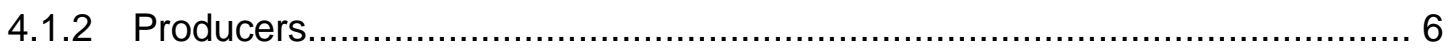

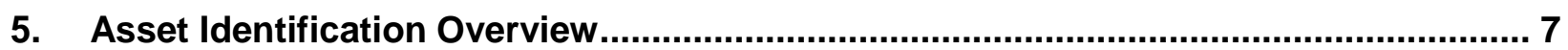

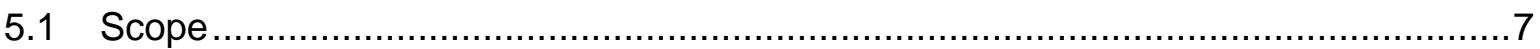

5.2 Core Specification and Extension Points ………..............................................

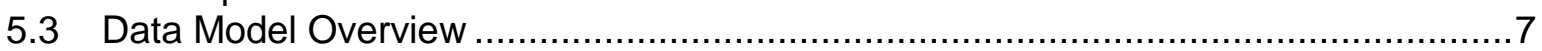

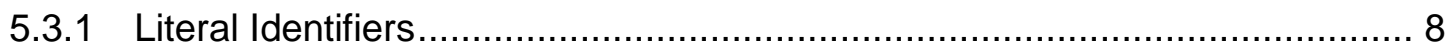

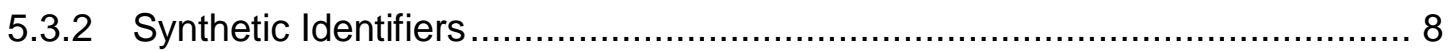

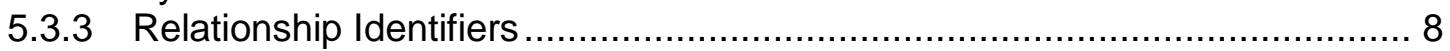

5.3.4 Extension Identifiers ................................................................ 9

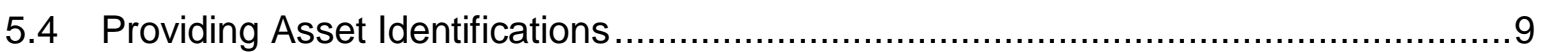

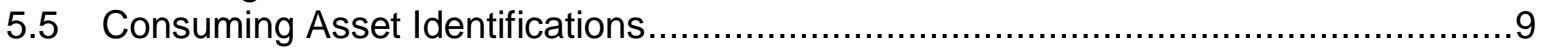

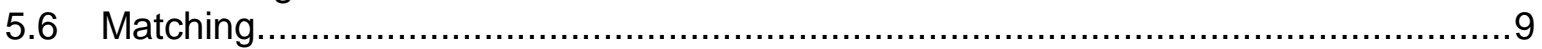

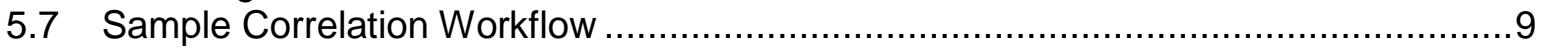

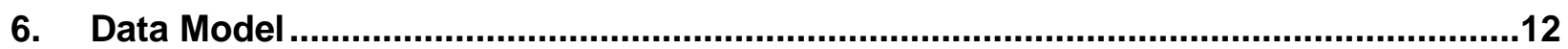

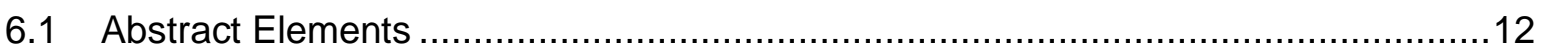

6.2 Concrete Asset Elements .......................................................................13

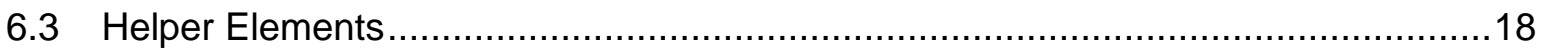

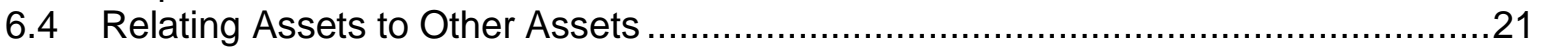

6.4.1 Relationship Data Model ............................................................21

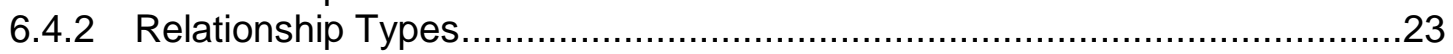

6.5 Guidance for Incorporating Asset Identification Elements into Other Data Models...25

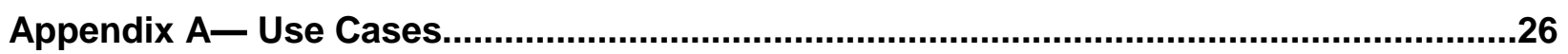

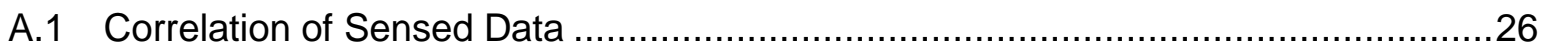

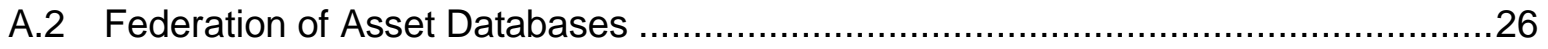

A.3 Directly Targeted Remediation Actions ..............................................................26

A.4 Management of Asset Data ………................................................................

Appendix B- Extending the Asset Identification Specification .......................................28

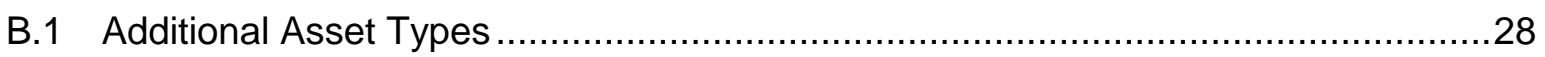

B.2 Additional Literal Identifiers for Existing Asset Types........................................28

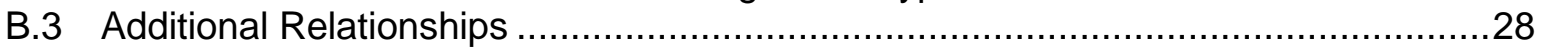


B.4 Additional Properties on Existing Data Elements ............................................28

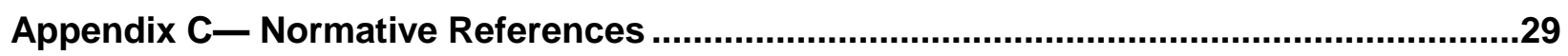

\section{List of Figures}

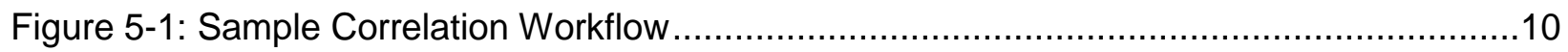

\section{List of Tables}

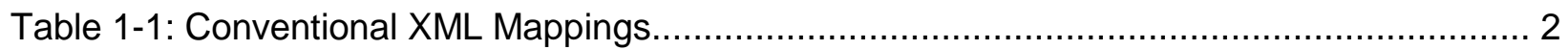

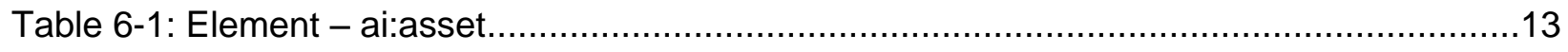

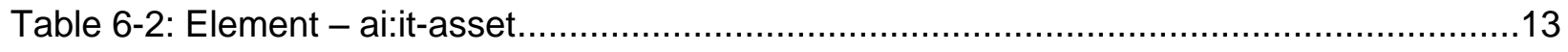

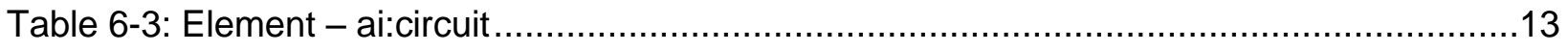

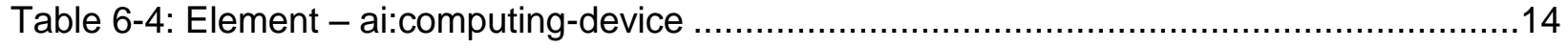

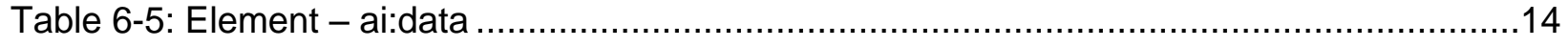

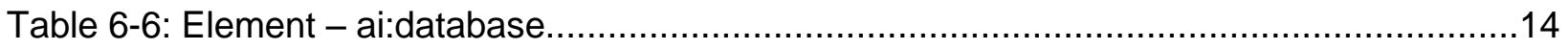

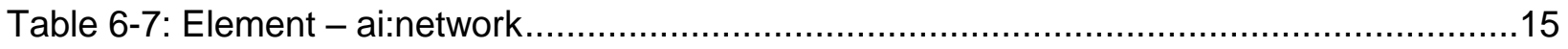

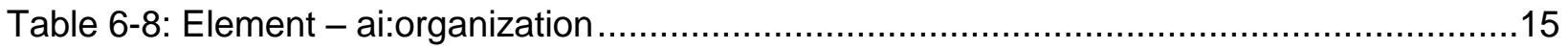

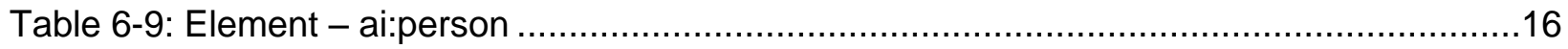

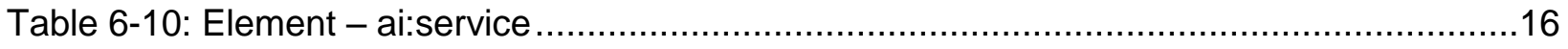

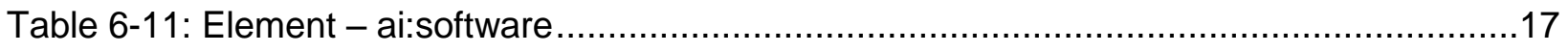

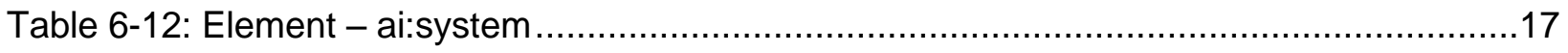

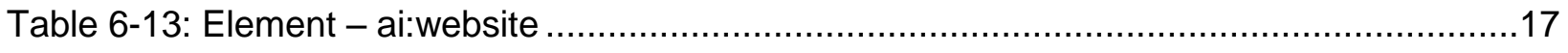

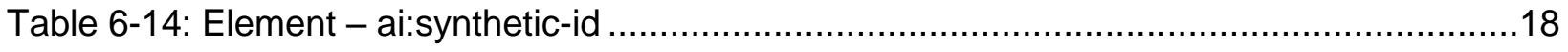

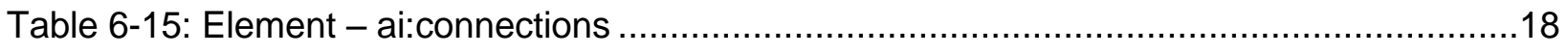

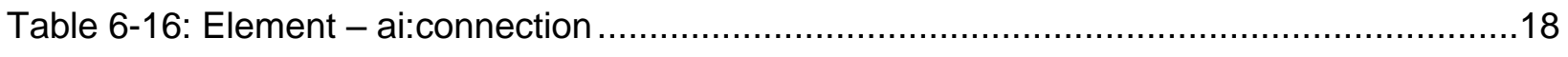

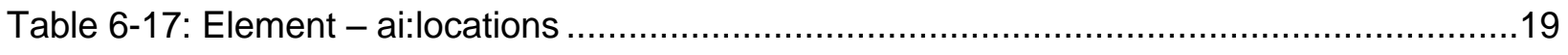

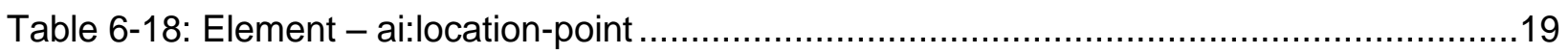

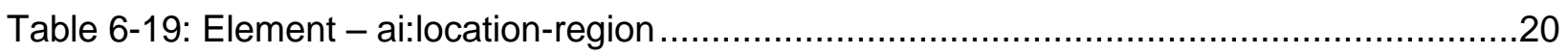

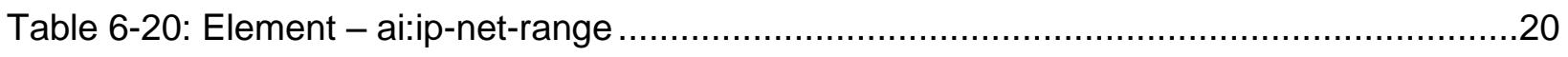

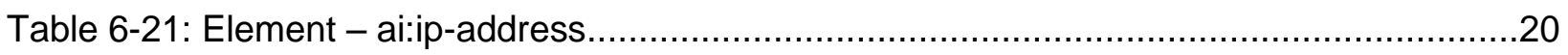

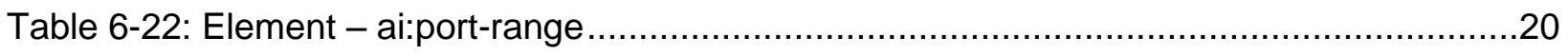

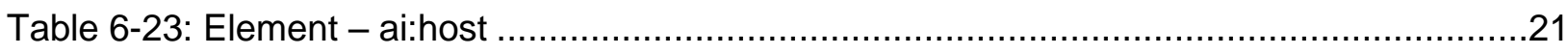

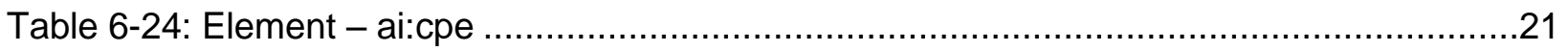




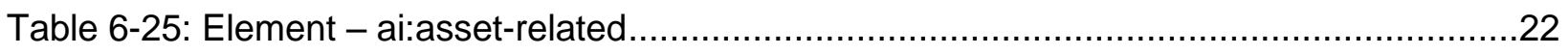

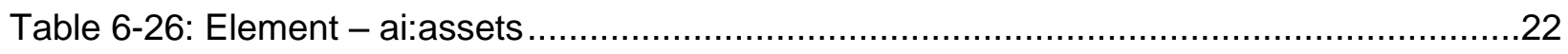

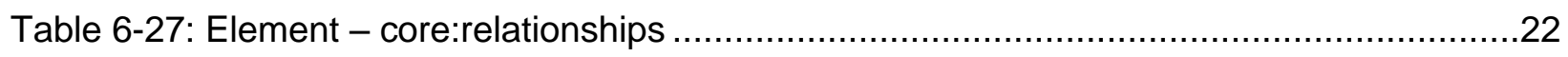

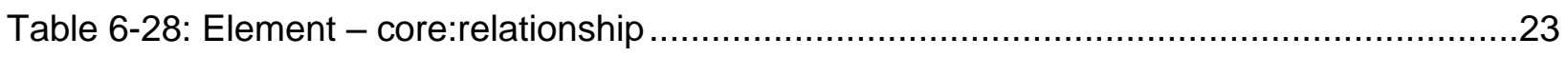

Table 6-29: Controlled Vocabulary Defined for Asset Identification ...................................24 


\section{Introduction}

One of the primary requirements for performing asset management is the ability to identify assets based on some set of data known about them. Asset identification, the use of attributes and methods to uniquely identify an asset, allows for correlation of data across multiple sources, reporting of asset information across different organizations and databases, targeted actions against specific assets, and usage of asset data in other business processes.

Unfortunately, neither a unified method nor a published specification for performing asset identification exists at this time. Existing security automation specifications either do not consider asset identification or represent identification information differently than other specifications with which they interoperate. This means that correlation of data relies on a transformation process between each specification, which is expensive and unreliable. Creation of such a unified method and specification for performing asset identification would allow for greater interoperability, increased capabilities, and easier implementation of asset management processes.

This Asset Identification specification describes a framework for how asset management processes and other specifications may identify assets using some set of information known or generated about the asset. It describes the data model and representation of asset identification information and it provides requirements for consuming and producing identification information. Requirements for usage of asset information and requirements for how the information that identifies assets is collected or generated are out of scope for this specification.

For the purposes of this specification, an asset is considered to be anything that has value to an organization. For example, computing devices are one form of asset that many organizations track. This specification, however, does not limit asset identification to identifying computing devices; any type of asset may be identified. The specification itself provides constructs for identifying many types of assets, and users may extend the model to include other asset types if they wish to identify asset types that are not addressed in the specification.

It is expected that other standards, data formats, tools, processes, and organizations will reference this specification to describe how to represent asset identification information. This will ensure compatibility of asset identifications among these components and allow for improved asset management processes.

While this specification was developed to support the immediate needs of the security automation community, it is expected that it will be valuable in general asset management processes both inside and outside of the security automation space.

\subsection{Purpose and Scope}

The purpose of this document is to define the Asset Identification specification, a standardized model for representing and identifying assets.

The scope of this document is to give an introduction to Asset Identification, give guidelines on using Asset Identification, describe the Asset Identification data model, and document conformance requirements to comply with Asset Identification. Other versions of Asset Identification and the associated component specifications, including emerging specifications and future versions, are not addressed here.

Future versions of Asset Identification will be defined in distinct revisions of this document, each clearly labeled with a document revision number and the appropriate Asset Identification version number. 


\subsection{Audience}

This specification is intended for authors of specifications that must support asset identifications, implementers of those specifications, system integrators composing architectures from tools that implement those specifications, and end users who wish to understand how these tools work.

\subsection{Document Structure}

The remainder of this document is organized into the following major sections:

- Section 2 defines the terms used within this specification and provides a list of common abbreviations.

- Section 3 describes how this specification fits with related standards and specifications.

- Section 4 defines the conformance requirements for asset identification.

- Section 5 gives an overview of asset identification.

- Section 6 describes the asset identification data model constructs.

- Appendix A describes possible use cases for asset identification.

- Appendix B explains how the specification can be extended.

- Appendix $\mathrm{C}$ documents the normative references for this specification

\subsection{Document Conventions}

Throughout this specification, whenever a specific term from the data model is referenced, as defined in Section 6, the term is written in Courier New font. When referencing a specification listed in Appendix B, the name will be written between brackets, such as [XML Schema].

The key words "MUST", "MUST NOT", "REQUIRED", "SHALL”, "SHALL NOT”, "SHOULD”, "SHOULD NOT", "RECOMMENDED", "MAY", and "OPTIONAL" in this document are to be interpreted as described in [RFC 2119].

Both inline and indented forms use qualified names to refer to specific XML elements. A qualified name associates a named element with a namespace. The namespace identifies the specific XML schema that defines (and consequently may be used to validate) the syntax of the element instance. A qualified name declares this schema to element association using the format 'prefix:element-name'. The association of prefix to namespace is defined in the metadata of an XML document and generally will vary from document to document. In this specification, the conventional mappings listed in Table 1-1 are used.

Table 1-1: Conventional XML Mappings

\begin{tabular}{|l|l|l|}
\hline Mappings Prefix & Namespace URI & Schema \\
\hline ai & http://scap.nist.gov/schema/asset-identification/1.1 & Asset Identification 1.1 \\
\hline core & http://scap.nist.gov/schema/reporting-core/1.1 & SCAP Reporting Core 1.1 \\
\hline cpe-name & http://cpe.mitre.org/naming/2.0 & CPE 2.3 Naming Specification \\
\hline xal & urn:oasis:names:tc:ciq:xsdschema:xAL:2.0 & OASIS extensible Address Language \\
\hline xnl & urn:oasis:names:tc:ciq:xsdschema:xNL:2.0 & OASIS extensible Name Language \\
\hline
\end{tabular}




\section{Terms and Abbreviations}

\subsection{Terms}

This section defines a set of common terms used within the document.

Asset: Anything that has value to an organization, including, but not limited to, another organization, person, computing device, information technology (IT) system, IT network, IT circuit, software (both an installed instance and a physical instance), virtual computing platform (common in cloud and virtualized computing), and related hardware (e.g., locks, cabinets, keyboards).

Asset Identification: The use of attributes and methods to uniquely identify an asset.

Asset Identification Element: A complete, bound expression of an asset identification using the constructs defined in this specification.

Circuit: A dedicated single connection between two endpoints on a network.

Computing Device: A machine (real or virtual) for performing calculations automatically (including, but not limited to, computer, servers, routers, switches, etc.)

Data: Any piece of information suitable for use in a computer.

Database: A repository of information or data, which may or may not be a traditional relational database system.

Extension Identifier: Any piece of identifying information provided in an asset identification element that is not explicitly defined in the Asset Identification schema.

Identifying Information: The set of an asset's attributes that may be useful for identifying that asset, including discoverable information about the asset and identifiers assigned to the asset.

Matching: The process of determining whether two or more asset identification expressions refer to the same asset.

Network: An information system(s) implemented with a collection of interconnected components. Such components may include routers, hubs, cabling, telecommunications controllers, key distribution centers, and technical control devices.

Organization: An entity of any size, complexity, or positioning within an organizational structure (e.g., a federal agency, or, as appropriate, any of its operational elements).

Person: Any person considered as an asset by the management domain.

Relationship Identifier: Identifying information where the value is a relationship to another asset.

Service: A set of related IT components provided in support of one or more business processes.

Software: Computer programs and associated data that may be dynamically written or modified during execution. 
System: A discrete set of information resources organized for the collection, processing, maintenance, use, sharing, dissemination, or disposition of information.

Synthetic Identifier: An identifier that is assigned to an asset in the context of some management domain.

Website: A set of related web pages that are prepared and maintained as a collection in support of a single purpose.

\subsection{Acronyms}

$\begin{array}{ll}\text { BIOS } & \text { Basic Input/Output System } \\ \text { CIDR } & \text { Classless Inter-Domain Routing } \\ \text { CPE } & \text { Common Platform Enumeration } \\ \text { FQDN } & \text { Fully-Qualified Domain Name } \\ \text { GUID } & \text { Globally Unique Identifier } \\ \text { HTTP } & \text { Hypertext Transfer Protocol } \\ \text { IETF } & \text { Internet Engineering Task Force } \\ \text { IP } & \text { Internet Protocol } \\ \text { IT } & \text { Information Technology } \\ \text { ITL } & \text { Information Technology Laboratory } \\ \text { MAC } & \text { Media Access Control } \\ \text { NIST } & \text { National Institute of Standards and Technology } \\ \text { OASIS } & \text { Organization for the Advancement of Structured Information Standards } \\ \text { RFC } & \text { Request for Comment } \\ \text { URI } & \text { Uniform Resource Identifier } \\ \text { URL } & \text { Uniform Resource Locator } \\ \text { W3C } & \text { World Wide Web Consortium } \\ \text { WFN } & \text { Well-Formed Name } \\ \text { XAL } & \text { extensible Address Language } \\ \text { XML } & \text { Extensible Markup Language } \\ \text { XNL } & \text { extensible Naming Language } \\ \text { XSD } & \text { XML Schema }\end{array}$




\section{Relationship to Existing Standards and Specifications}

This specification defines the constructs and methods for representing asset identification information and thus can be leveraged by any other specification where identifying assets is required or beneficial.

This specification uses several industry-standard mechanisms for representing identification information and providing conformance requirements.

Common Platform Enumeration $(\mathrm{CPE})^{\mathrm{TM}}$ is a structured naming scheme for information technology systems, platforms, and packages. Based upon the generic syntax for Uniform Resource Identifiers (URI), CPE includes a formal name format. CPE version 2.3 Well-Formed Names (WFN) are used as softwareidentifying information by this specification.

The extensible Address Language (xAL) by the Organization for the Advancement of Structured Information Standards (OASIS) is an XML standard format for representing international address information. Asset Identification leverages XAL to represent address information for assets.

The extensible Name Language (xNL) by OASIS is an XML standard format for representing the names of people and organizations. Asset Identification leverages xNL to represent the names of people and organizations. 


\section{Conformance}

A product may want to claim conformance with this specification so that users and organizations can use the product with the assurance that the product can identify assets in a consistent and standard manner. The ability for a product to identify assets in a standard manner increases the likelihood of interoperability between conforming products. This section defines the criteria for products to claim conformance with this specification.

\subsection{Product Conformance}

Products are divided into two roles based on their use of asset identification information: consumers and producers.

- Consuming products ("consumers") must be able to receive and understand information in compliance with this specification.

- Producing products ("producers") must create asset identification information in a format compliant with this specification.

A product may be both a consumer and producer. The following subsections document the conformance requirements for the two types of products.

\subsubsection{Consumers}

Any consuming product claiming conformance to this specification MUST adhere to the following requirements.

- The consumer SHALL be capable of processing the identification information represented in constructs consistent with the Asset Identification data model without error. REF: Section 6

- The consumer MAY attempt to consume constructs that are invalid per the Asset Identification data model. REF: Section 6

- The consumer MAY consume extension identifiers and use them as an input into a matching process. REF: Section 5.3.4

- The consumer MUST NOT abnormally end, crash, or otherwise be unable to fully process asset identification elements that include extension identifiers. It MAY ignore any information in extension identifiers.

\subsubsection{Producers}

Any producing product claiming conformance to this specification MUST adhere to the following requirements.

- The producer SHALL accurately produce the asset identification element in XML consistent with the data model. REF: Section 6

- When representing identification information, the producer SHOULD provide as much information as is sufficient to allow for a match. REF: Section 5.3

- When representing identification information, the producer MAY provide as much or as little identifying information as allowed in the data model per other recommendations or tool capabilities. REF: Section 5.3

- The producer MAY provide extension identifiers for any asset identification element. REF: Section 5.3.4 


\section{Asset Identification Overview}

This section gives an overview of the Asset Identification specification and its key concepts.

\subsection{Scope}

In order to support the variety of use cases discussed in Appendix A, the scope of this specification is limited to a description of how asset management tools can represent asset identification information when communicating it to other tools. It is out of scope of this specification to recommend which identifiers to use or to require that identification information be collected in a certain way or from a certain place. Higher-level specifications, tools, and organizations that implement Asset Identification, however, are encouraged to make these recommendations or specify these requirements in order to support the particular needs of their use cases.

Additionally, the Asset Identification specification is not a mechanism for expressing information about an asset that is not related to asset identification. Only elements that are used for identification are included in the core specification. Asset Identification elements MUST NOT be used to represent information about an asset unless it is being used to identify that asset.

\subsection{Core Specification and Extension Points}

The core Asset Identification specification defines eleven asset types and definitions of how those asset types may be identified using a set of literal attributes and relationships to other assets. The core specification is intended to provide definitions for commonly used asset types and identification attributes; it is not intended to be an exhaustive list of all possible asset types and attributes that may be used for identification. Anything explicitly defined in the asset identification schema and the asset identification controlled vocabulary for relationship identifiers is considered part of the core specification.

There are several extension points in the Asset Identification data model to allow for identification of asset types beyond what is included in the core specification and to allow attributes or relationships outside of the core specification to be used to identify asset types that are included. These extension points are:

- Additional asset types may be created by inheriting from any concrete or abstract "asset" data element in the core XML schema.

- The core asset types may be enhanced by adding elements to the appropriate asset type as literal values in the "extended-information" element.

- Additional relationships can be defined by creating a separate vocabulary for relationship identifiers.

\subsection{Data Model Overview}

The Asset Identification data model consists of a set of asset types and a set of information that can be provided about each asset type. The asset types currently supported in this specification are:

- Person

- Organization

- System

- Software

- Database 
- Network

- Service

- Data

- Computing Device

- Circuit

- Website

For the purposes of this specification the above asset types MUST be understood as defined in Section 2.1 .

The specification MAY be extended by Asset Identification producers to allow for other asset types as needed; however, it is OPTIONAL for Asset Identification consumers to support asset types not present in the core specification.

For each asset type above, the specification has a core set of fields that may be provided in order to identify an asset of that type. For example, an asset of type "person" may be identified by an email address, full name, telephone number, or birth date. Any number of these fields may be populated in order to create an asset identification element. Specifications, management environments, organizations, and tool vendors implementing Asset Identification are encouraged to recommend, restrict, or require that certain fields be populated or not populated; however, the specification itself does not do so.

There are several different types of information that may be used to identify assets: literal identifiers, relationship identifiers, synthetic identifiers, and extension identifiers. These four identifier types are differentiated only because they are represented differently in the data model. No identifier type is intrinsically more or less valuable for performing asset identification than any other identifier type.

\subsubsection{Literal Identifiers}

Literal identifiers are the pre-defined fields containing literal values that may identify an asset. For example, Media Access Control (MAC) address is an example of a literal identifier for a computing device. Literal identifiers defined in Asset Identification MUST be properly processed without error by Asset Identification consumers.

\subsubsection{Synthetic Identifiers}

Synthetic identifiers are meant to be used when a database or process assigns an identifier. For example, an employee is often assigned an employee identifier which may be used to track him or her across the organization. These identifiers should be represented using the synthetic identifier construct: the namespace denotes the management domain for which the identifier is valid and the identifier contains the identifier itself. Each asset type allows for a list of zero to many synthetic identifiers. Synthetic identifiers MUST be properly processed without error by Asset Identification consumers.

\subsubsection{Relationship Identifiers}

Relationship identifiers are meant to be used when an asset may be identified based on a relationship to another asset. For example, a system may be identified based on the fact that it is named "System 1" and it is connected to network "INTERNAL". Relationship types are represented as a controlled vocabulary. Any relationships defined in the Asset Identification controlled vocabulary are core and MUST be processed without error by Asset Identification consumers. Relationships that are defined in other controlled vocabularies are considered extension identifiers and MAY be supported by Asset Identification consumers. 


\subsubsection{Extension Identifiers}

Although this specification intends to support the most common types of information that are used to identify assets, certain users, organizations, or use cases may find that the core model does not support some fields that they need. Asset Identification supports a producer's ability to provide these identifiers in any asset identification element through extension identifiers; however, it is OPTIONAL for consumers to process or understand these identifiers unless some other specification requires it. Extension identifiers may include additional literal values as well as relationship identifiers that are outside of the Asset Identification controlled vocabulary. Extension identifiers MUST be processed without error by consumers; however, consumers are encouraged to ignore identifying information that they do not understand and is not defined in the core schema, which ensures accurate correlation.

\subsection{Providing Asset Identifications}

In the absence of other guidance or requirements, Asset Identification providers SHOULD provide as much information as they have available in the core (non-extension) asset identification element. Bandwidth constraints, other specifications, and tool intelligence MAY help define how much or which information SHOULD be provided beyond this recommendation.

\subsection{Consuming Asset Identifications}

Asset Identification consumers MUST be able to process literal identifiers, synthetic identifiers, relationship identifiers, and extension identifiers without error. In this context, "process" simply means ingest without error and optionally use as an input in performing a matching. Asset Identification consumers SHOULD process literal identifiers, synthetic identifiers, and relationship identifiers and support incorporating them into a matching process. Asset Identification consumers SHOULD NOT incorporate unknown extended identifiers into a matching process as they may be misleading or misunderstood.

Extended identifiers that are defined in another specification or policy that the consumer implements MAY be supported as appropriate and as defined by that specification or policy.

\subsection{Matching}

Matching is the process of determining whether or not two or more asset identification elements are referring to the same asset. Matching is performed across an entire asset identification element, not across each individual property of an identifier.

Although matching identifiers is an important part of the asset identification process, due to a wide variety of current tool practices, organizational architectures, and the need to allow for innovation, this specification does not provide any normative requirements in regards to matching. Tools are free to perform matching based on their own logic, and specifications implementing asset identification are encouraged to provide their own recommendations or requirements around matching.

\subsection{Sample Correlation Workflow}

The diagram in Figure 5-1 shows a sample correlation workflow, including matching discoverable information and several synthetic identifiers. 
In this sample architecture, which is merely one example, several tools report on information about an asset. The information is correlated by an asset database, potentially processed or aggregated, and then reported to a higher-level database.

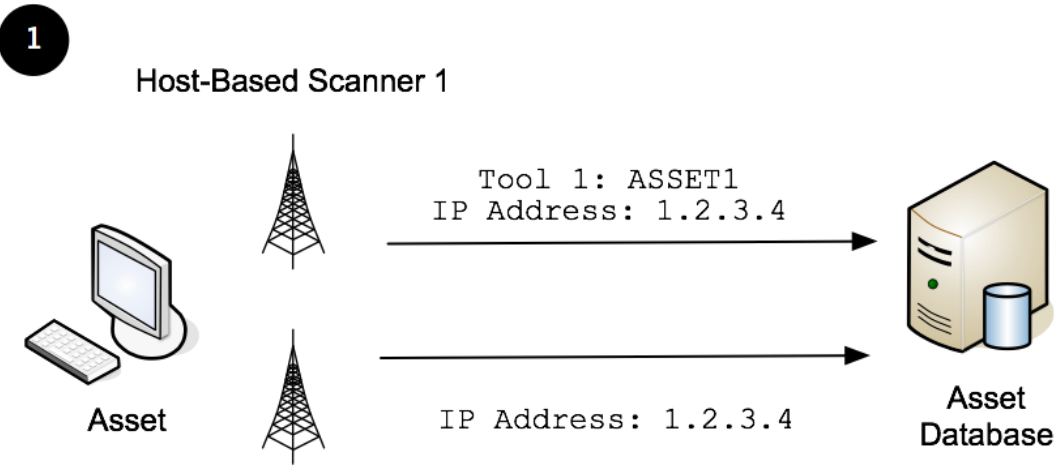

Network-Based Scanner

\section{2}
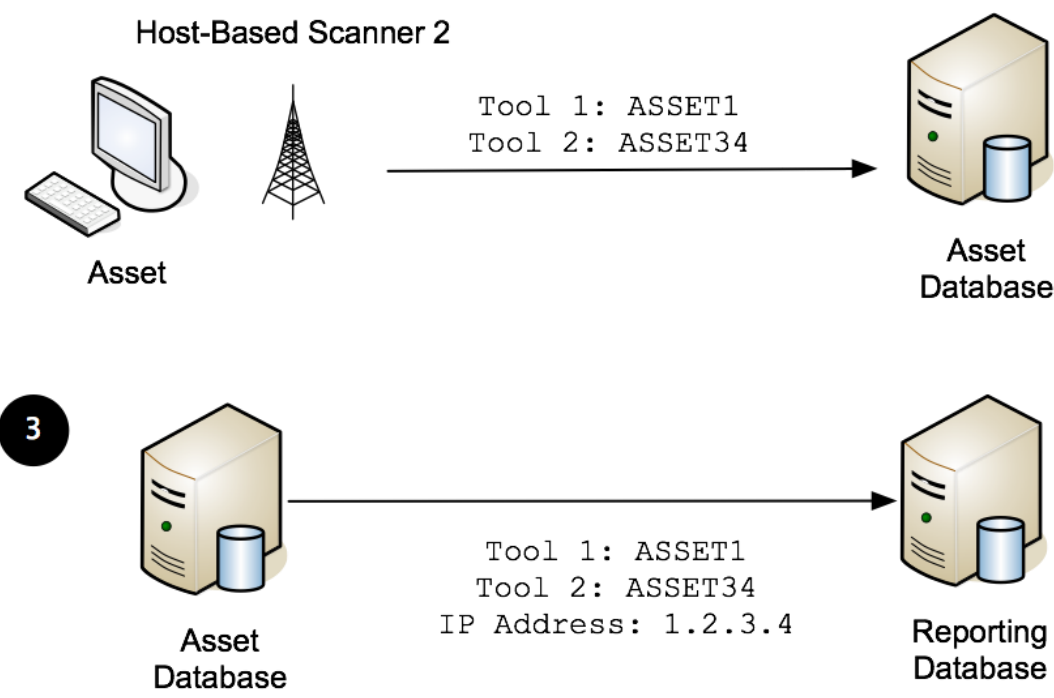

Figure 5-1: Sample Correlation Workflow

In step 1, a host-based scanner is reporting on asset information (e.g. vulnerability assessment results) using a synthetic identifier in its own namespace and an IP address as identifying information.

Additionally, a network scanner is reporting on network events by IP address. This allows the asset database to correlate information coming from the network with information on the host, potentially matching vulnerabilities discovered by the host-based scanner with attacks against that vulnerability discovered by the network scanner.

In step 2, another host-based scanner (e.g., an asset inventory tool) reports data using both a synthetic identifier in its own namespace and a synthetic identifier in the first host-based tool's namespace. This other identifier may have been collected on the system or may have been discovered some other way; 
how that collection happens is out of scope of this specification. By passing both identifiers, however, the scanner provides enough data to the asset database to correlate the additional inventory data with the vulnerability and event data. Additionally, any other data reported using either the IP address or the two synthetic identifiers will be able to be correlated as well. Note that this specification does not require or recommend that tools process identifiers in certain ways: for example, an IP address may become stale after a period of time, but it is out of scope for this specification to recommend how to deal with that.

In step 3, the asset database provides a report to a higher-level database. Depending on the reporting architecture, organizational hierarchy, and reporting requirements, asset databases may want to report on data with different sets of synthetic identifiers for each asset. This specification does not restrict or recommend architectures or workflows.

In the reporting architecture shown above, all known asset identifiers for each asset are being used to report information to the higher level. In this architecture, data provided by other tools to the higher-level database may be correlated with the reported data. Other options would be to only report some information to the higher-level database or even to generate a new synthetic identifier to perform reporting, depending on the reporting requirements and network architectures. 


\section{Data Model}

This section documents the data model for Asset Identification. The XML schema that implements this data model is provided separate from this specification.

The Asset Identification model is a fairly flat model that defines the constructs to hold identifying information about an asset. A limited number of asset types are defined for which model constructs exist. In order to use the Asset Identification model:

- The user SHOULD produce an XML ai:assets or ai:asset-related element consistent with the data model described in Section 6.4.1.

- The XML element produced MUST validate against the XML schema (XSD) for Asset Identification 1.1 at http://scap.nist.gov/specifications/ai/index.html. In situations where the XML schema does not match the documented model in this specification, the XSD takes precedence.

The following tables formalize the logical data model. The data contained in the tables are requirements and MUST be interpreted as follows:

- The "Element Name" field indicates the name for the entity being described.

- The "Definition" field indicates the prose description of the text. The field MAY contain requirement words as indicated in RFC 2119.

- The "Inherits" field indicates that the element takes on all of the properties of the inherited element in addition to the properties defined for the element.

- The "Properties" field is broken into four columns:

- The "Name" column indicates the name of a property that MAY or MUST be included in the described element in accordance with the cardinality indicated in the "Count" field.

- The "Type" column indicates the type of data that MUST be the value for the property. There are two categories of types: literal and element. A literal type will indicate the type of literal. The element type will reference the name of another element that defines the content for that property.

- The "Count" column indicates the cardinality of the property within the element. The property MUST be included in the element in accordance with the cardinality. If a range is given, and " $n$ " is the upper-bound of the range, then the upper limit is unbounded.

○ The "Definition" column defines the property in the context of the element. The field MAY contain requirement words as indicated in RFC 2119.

Each literal data element MAY have a "source" attribute associated with it. The source attribute is intended to capture the source of the information for that data element. The field SHALL be a string type, but the value of the field is left to the content producer. The value MAY include, but is not restricted to, a synthetic ID of the asset that sourced the information, another ID of the source, or a description of the source. See the XSD for additional clarity on the "source" attribute.

Each literal data element MAY have a "timestamp" attribute associated with it. If populated, the timestamp attribute indicates when the data was last known to be correct for that element.

\subsection{Abstract Elements}

The elements described in this section are the top-level abstract elements from which all asset elements derive. 
Table 6-1: Element - ai:asset

\begin{tabular}{|l|l|l|l|l|}
\hline Element Name: ai:asset \\
\hline Definition & $\begin{array}{l}\text { The root element from which all other asset elements derive. This element does not } \\
\text { represent any specific type of asset, and therefore should only be used as a base class for } \\
\text { other, concrete, asset elements. Any element that claims to be an asset element compliant } \\
\text { with this specification SHALL directly or indirectly inherit all of the attributes in this } \\
\text { element. The asset element SHALL NOT be used directly in an asset identification } \\
\text { instance because it is abstract. }\end{array}$ \\
\hline \multirow{1}{*}{ Properties } & Name & Type & Count & Definition \\
\cline { 2 - 5 } & synthetic-id & element - synthetic-id & $0-n$ & $\begin{array}{l}\text { Holds the synthetic ID information for } \\
\text { the asset. }\end{array}$ \\
\cline { 2 - 6 } & locations & element - locations & $0-1$ & $\begin{array}{l}\text { Holds the location information where } \\
\text { the asset resides. }\end{array}$ \\
\cline { 2 - 5 } & $\begin{array}{l}\text { extended- } \\
\text { information }\end{array}$ & element - any XML & $0-1$ & $\begin{array}{l}\text { Holds extension identifiers for the } \\
\text { asset. The content can be any well- } \\
\text { formed XML defined in a namespace } \\
\text { other than the Asset Identification } \\
\text { namespace. }\end{array}$ \\
\cline { 2 - 5 } & timestamp & literal - dateTime & $0-1$ & $\begin{array}{l}\text { The date and time when the } \\
\text { information was last known to be } \\
\text { correct. }\end{array}$ \\
\hline
\end{tabular}

Table 6-2: Element - ai:it-asset

\begin{tabular}{|l|l|}
\hline \multicolumn{2}{|l|}{ Element Name: ai:it-asset } \\
\hline Inherits & ai:asset \\
\hline Definition & $\begin{array}{l}\text { An abstract element that extends from the asset element. it-asset is a placeholder element } \\
\text { to carry common attributes related to IT assets. For the current iteration of this } \\
\text { specification no common attributes have been identified, but future iterations of the } \\
\text { specification MAY contain common attributes for IT assets. All asset elements that are } \\
\text { describing IT assets SHOULD extend from the it-asset element. }\end{array}$ \\
\hline
\end{tabular}

\subsection{Concrete Asset Elements}

The following elements describe the data elements for the asset types defined in this specification.

Table 6-3: Element - ai:circuit

\begin{tabular}{|l|l|l|l|l|}
\hline \multicolumn{3}{|l|}{ Element Name: ai:circuit } \\
\hline Inherits & \multicolumn{3}{|l|}{ ai:it-asset } \\
\hline Definition & Captures identifying information about a circuit. \\
\hline \multirow{2}{*}{ Properties } & Name & Type & Count & Definition \\
\cline { 2 - 5 } & circuit-name & literal - token & $0-1$ & The name of the circuit being identified. \\
\hline
\end{tabular}


Table 6-4: Element - ai:computing-device

\begin{tabular}{|c|c|c|c|c|}
\hline \multicolumn{5}{|c|}{ Element Name: ai:computing-device } \\
\hline Inherits & \multicolumn{4}{|c|}{ ai:it-asset } \\
\hline Definition & \multicolumn{4}{|c|}{ Captures identifying information about a computing device. } \\
\hline \multirow{7}{*}{ Properties } & Name & Type & Count & Definition \\
\hline & $\begin{array}{l}\text { distinguished- } \\
\text { name }\end{array}$ & literal - token & $0-1$ & $\begin{array}{l}\text { The X.500 distinguished name of the } \\
\text { computing device being identified. }\end{array}$ \\
\hline & cpe & literal - ai:cpe & $0-\mathrm{n}$ & $\begin{array}{l}\text { The Common Platform Enumeration name for } \\
\text { the computing device being identified. This } \\
\text { MUST be a hardware CPE. This MUST be a } \\
\text { CPE } 2.2 \text { URI [CPE22] or CPE } 2.3 \text { formatted } \\
\text { string [CPE23]. }\end{array}$ \\
\hline & connections & $\begin{array}{l}\text { element - } \\
\text { ai:connections }\end{array}$ & $0-1$ & $\begin{array}{l}\text { Information about a network interface on the } \\
\text { computing device being identified. }\end{array}$ \\
\hline & fqdn & literal - token & $0-1$ & $\begin{array}{l}\text { The fully-qualified domain name for the } \\
\text { computing device being identified. }\end{array}$ \\
\hline & hostname & literal - token & $0-1$ & The hostname of the computing device. \\
\hline & $\begin{array}{l}\text { motherboard- } \\
\text { guid }\end{array}$ & literal - string & $0-1$ & $\begin{array}{l}\text { The motherboard globally unique identifier of } \\
\text { the computing device. }\end{array}$ \\
\hline
\end{tabular}

Table 6-5: Element - ai:data

\begin{tabular}{|l|l|}
\hline \multicolumn{2}{|l|}{ Element Name: ai:data } \\
\hline Inherits & ai:asset \\
\hline Definition & $\begin{array}{l}\text { A generic element to describe any type of data. Since this element is generic it does not } \\
\text { define any of its own properties, but instead relies solely on the properties inherited from } \\
\text { asset. }\end{array}$ \\
\hline
\end{tabular}

Table 6-6: Element - ai:database

\begin{tabular}{|l|l|l|l|l|}
\hline Element Name: ai:database \\
\hline Inherits & ai:it-asset \\
\hline Definition & Captures identifying information about a database. \\
\hline Properties & Name & Type & Count & Definition \\
\hline & instance-name & literal - token & $0-1$ & The name of the database instance. \\
\hline
\end{tabular}


Table 6-7: Element - ai:network

\begin{tabular}{|c|c|c|c|c|}
\hline \multicolumn{5}{|c|}{ Element Name: ai:network } \\
\hline Inherits & \multicolumn{4}{|c|}{ ai:it-asset } \\
\hline Definition & \multicolumn{4}{|c|}{ Captures identifying information about a network. } \\
\hline \multirow[t]{4}{*}{ Properties } & Name & Type & Count & Definition \\
\hline & network-name & $\begin{array}{l}\text { literal - } \\
\text { normalizedString }\end{array}$ & $0-1$ & The name of the network being identified. \\
\hline & ip-net-range & $\begin{array}{l}\text { element - } \\
\text { ip-net-range }\end{array}$ & \multirow{2}{*}{$\begin{array}{l}0-1 \\
\text { (either } \\
\text { but } \\
\text { not } \\
\text { both) }\end{array}$} & $\begin{array}{l}\text { The starting and ending IP addresses for the } \\
\text { range of IP addresses for the network being } \\
\text { identified. }\end{array}$ \\
\hline & cidr & literal - token & & $\begin{array}{l}\text { The Classless Inter-Domain Routing } \\
\text { information for the network being } \\
\text { identified. }\end{array}$ \\
\hline
\end{tabular}

Table 6-8: Element - ai:organization

\begin{tabular}{|c|c|c|c|c|}
\hline \multicolumn{5}{|c|}{ Element Name: ai:organization } \\
\hline \multirow{2}{*}{\begin{tabular}{|l} 
Inherits \\
Definition \\
\end{tabular}} & \multicolumn{4}{|c|}{ ai:asset } \\
\hline & \multicolumn{4}{|c|}{ Captures identifying information about an organization. } \\
\hline \multirow[t]{5}{*}{ Properties } & Name & Type & Count & Definition \\
\hline & $\begin{array}{l}\text { xnl:Organisation } \\
\text { NameDetails }\end{array}$ & $\begin{array}{l}\text { element - } \\
\text { xnl:Organisation } \\
\text { NameDetails }\end{array}$ & $0-n$ & $\begin{array}{l}\text { The name of the organization being } \\
\text { identified. See }[\mathrm{xNL}] \text { for details on } \\
\text { populating this element. }\end{array}$ \\
\hline & email-address & literal - token & $0-n$ & $\begin{array}{l}\text { An email address associated with the } \\
\text { organization being identified. }\end{array}$ \\
\hline & $\begin{array}{l}\text { telephone- } \\
\text { number }\end{array}$ & literal - token & $0-n$ & $\begin{array}{l}\text { A phone number associated with the } \\
\text { organization being identified. For a North } \\
\text { American number, the number MUST be } \\
\text { valid and the format MUST be XXX- } \\
\text { XXX-XXXX where X is a digit. For an } \\
\text { international number, the number MUST } \\
\text { begin with a '+' symbol, followed by } 7 \text { to } \\
15 \text { digits. A space MAY be used between } \\
\text { digits, as appropriate. For example: }+88 \\
8888888 \text { (this is following the ITU-T } \\
\text { E.123 notation). } \\
\text { Regex: }(([2-9][0-8] \backslash d-[2-9] \backslash d\{2\}-[0- \\
9]\{4\}) \mid((+([0-9] ?)\{6,14\}[0-9]))\end{array}$ \\
\hline & website-url & literal - URL & $0-n$ & $\begin{array}{l}\text { A website associated with the organization } \\
\text { being identified. }\end{array}$ \\
\hline
\end{tabular}


Table 6-9: Element - ai:person

\begin{tabular}{|c|c|c|c|c|}
\hline \multicolumn{5}{|c|}{ Element Name: ai:person } \\
\hline Inherits & \multicolumn{4}{|l|}{ ai:asset } \\
\hline Definition & \multicolumn{4}{|c|}{ Captures identifying information about a person. } \\
\hline \multirow{5}{*}{ Properties } & Name & Type & Count & Definition \\
\hline & xnl:PersonName & $\begin{array}{l}\text { element - } \\
\text { xnl:PersonName }\end{array}$ & $0-1$ & $\begin{array}{l}\text { The name of the person being identified. } \\
\text { The element type is defined in [xNL] and } \\
\text { SHALL be used as documented in that } \\
\text { specification. }\end{array}$ \\
\hline & email-address & literal - token & $0-n$ & $\begin{array}{l}\text { An email address associated with the } \\
\text { person being identified. }\end{array}$ \\
\hline & $\begin{array}{l}\text { telephone- } \\
\text { number }\end{array}$ & literal - token & $0-n$ & $\begin{array}{l}\text { A phone number associated with the } \\
\text { person being identified. For a North } \\
\text { American number, the number MUST be } \\
\text { valid and the format MUST be XXX- } \\
\text { XXX-XXXX where X is a digit. For an } \\
\text { international number, the number MUST } \\
\text { begin with a '+' symbol, followed by } 7 \text { to } \\
15 \text { digits. A space MAY be used between } \\
\text { digits, as appropriate. For example: }+88 \\
8888888 \text { (this is following the ITU-T } \\
\text { E.123 notation). } \\
\text { Regex: }(([2-9][0-8] \backslash d-[2-9] \backslash d\{2\}-[0- \\
9]\{4\}) \mid(+([0-9] \text { ?) }\{6,14\}[0-9]))\end{array}$ \\
\hline & birthdate & literal - date & $0-1$ & $\begin{array}{l}\text { The birth date of the person being } \\
\text { identified. }\end{array}$ \\
\hline
\end{tabular}

Table 6-10: Element - ai:service

\begin{tabular}{|l|l|l|l|l|}
\hline \multicolumn{2}{|l|}{ Element Name: ai:service } \\
\hline Inherits & \multicolumn{2}{|l|}{ ai:it-asset } \\
\hline Definition & Captures identifying information about a service running on a computing-device. \\
\hline \multirow{1}{*}{ Properties } & Name & Type & Count & Definition \\
\cline { 2 - 5 } & host & $\begin{array}{l}\text { element - } \\
\text { host }\end{array}$ & $0-1$ & $\begin{array}{l}\text { The IP address or fully qualified domain name of the } \\
\text { host of the service. }\end{array}$ \\
\cline { 2 - 5 } & port & $\begin{array}{l}\text { literal - } \\
\text { integer }\end{array}$ & $0-n$ & $\begin{array}{l}\text { The port number that the service is bound to. } \\
\text { Restricted to 0 <= x <= 65535 }\end{array}$ \\
\cline { 2 - 5 } & $\begin{array}{l}\text { port- } \\
\text { range }\end{array}$ & $\begin{array}{l}\text { element - } \\
\text { ai:port-range }\end{array}$ & $0-n$ & $\begin{array}{l}\text { The lower and upper bound (inclusive) of the range of } \\
\text { ports the service is bound to. }\end{array}$ \\
\cline { 2 - 5 } & protocol & $\begin{array}{l}\text { literal - } \\
\text { string }\end{array}$ & $0-1$ & $\begin{array}{l}\text { The protocol used to interact with the service (e.g., } \\
\text { HTTP, JMS, SSH, FTP). }\end{array}$ \\
\hline
\end{tabular}


Table 6-11: Element - ai:software

\begin{tabular}{|l|l|l|l|l|}
\hline Element Name: ai:software \\
\hline Inherits & \multicolumn{3}{|l|}{ ai:it-asset } & \multicolumn{3}{|l|}{} \\
\hline Definition & Captures identifying information about a class of software or a software instance. \\
\hline Properties & Name & Type & Count & Definition \\
\hline & installation-id & $\begin{array}{l}\text { literal - } \\
\text { token }\end{array}$ & $0-1$ & $\begin{array}{l}\text { Any identifier for a software instance (installation). } \\
\text { Use when identifying an instance of software and not } \\
\text { just the class of software. }\end{array}$ \\
\cline { 2 - 6 } & cpe & $\begin{array}{l}\text { literal - } \\
\text { ai:cpe }\end{array}$ & $0-1$ & $\begin{array}{l}\text { The Common Platform Enumeration name for the } \\
\text { class of software being identified. This MUST be a } \\
\text { software CPE. This MUST be a CPE 2.2 URI } \\
\text { [CPE22] or CPE 2.3 formatted string [CPE23]. }\end{array}$ \\
\cline { 2 - 5 } & license & $\begin{array}{l}\text { literal - } \\
\text { string }\end{array}$ & $0-n$ & $\begin{array}{l}\text { The license key associated with the software instance } \\
\text { (installation). Use when identifying an instance of } \\
\text { software and not just the class of software. }\end{array}$ \\
\hline
\end{tabular}

Table 6-12: Element - ai:system

\begin{tabular}{|l|l|l|l|l|}
\hline \multicolumn{2}{|l|}{ Element Name: ai:system } \\
\hline Inherits & \multicolumn{2}{|l|}{ ai:it-asset } \\
\hline Definition & Captures identifying information about a system. \\
\hline \multirow{3}{*}{ Properties } & Name & Type & Count & Definition \\
\cline { 2 - 5 } & $\begin{array}{l}\text { system- } \\
\text { name }\end{array}$ & $\begin{array}{l}\text { literal - } \\
\text { token }\end{array}$ & 0 -n & $\begin{array}{l}\text { The name of the system being identified. This property } \\
\text { can be replicated as systems may have multiple, or } \\
\text { abbreviated, names. All of the names (including } \\
\text { acronyms) MAY be captured here. }\end{array}$ \\
\cline { 2 - 5 } & version & $\begin{array}{l}\text { literal - } \\
\text { token }\end{array}$ & $0-1$ & The version of the system being identified. \\
\hline
\end{tabular}

Table 6-13: Element - ai:website

\begin{tabular}{|c|c|c|c|c|}
\hline \multicolumn{5}{|c|}{ Element Name: ai:website } \\
\hline Inherits & \multicolumn{4}{|c|}{ ai:it-asset } \\
\hline Definition & \multicolumn{4}{|c|}{ Captures identifying information about a website. } \\
\hline \multirow[t]{3}{*}{ Properties } & Name & Type & Count & Definition \\
\hline & $\begin{array}{l}\text { document- } \\
\text { root }\end{array}$ & $\begin{array}{l}\text { literal - } \\
\text { token }\end{array}$ & $0-1$ & $\begin{array}{l}\text { The absolute path to the document root location of the } \\
\text { website on the host. }\end{array}$ \\
\hline & locale & $\begin{array}{l}\text { literal - } \\
\text { token }\end{array}$ & $0-1$ & $\begin{array}{l}\text { The locale of the website represented as an RFC } 5646 \\
\text { language, and optionally, region code. Language and } \\
\text { region codes SHOULD be in the Internet Assigned } \\
\text { Numbers Authority (IANA) Language Subtag Registry } \\
\text { [ILSR]. } \\
\text { Regex: [a-zA-Z]\{2,3\}(-([a-zA-Z]\{2\}|[0-9]\{3\}))? }\end{array}$ \\
\hline
\end{tabular}




\subsection{Helper Elements}

Table 6-14: Element - ai:synthetic-id

\begin{tabular}{|l|l|l|l|l|}
\hline \multicolumn{5}{|l|}{ Element Name: ai:synthetic-id } \\
\hline Definition & Holds the synthetic identifier information for an asset. \\
\hline Properties & Name & Type & Count & Definition \\
\cline { 2 - 5 } & resource & $\begin{array}{l}\text { literal - } \\
\text { URI }\end{array}$ & 1 & $\begin{array}{l}\text { A URI for the namespace in which the identifier is } \\
\text { governed and unique. }\end{array}$ \\
\cline { 2 - 5 } & id & $\begin{array}{l}\text { literal - } \\
\text { token }\end{array}$ & 1 & $\begin{array}{l}\text { The unique identifier for the asset within the resource } \\
\text { namespace. }\end{array}$ \\
\hline
\end{tabular}

Table 6-15: Element - ai:connections

\begin{tabular}{|l|l|l|l|l|}
\hline \multicolumn{3}{|l|}{ Element Name: ai:connections } \\
\hline Definition & Contains a list of ai:connection elements. \\
\hline \multirow{3}{*}{ Properties } & Name & Type & Count & Definition \\
\cline { 2 - 5 } & connection & $\begin{array}{l}\text { element }- \\
\text { ai:connection }\end{array}$ & $1-n$ & $\begin{array}{l}\text { Information about a network interface on the } \\
\text { computing device being identified. }\end{array}$ \\
\hline
\end{tabular}

Table 6-16: Element - ai:connection

\begin{tabular}{|c|c|c|c|c|}
\hline \multicolumn{5}{|c|}{ Element Name: ai:connection } \\
\hline Definition & \multicolumn{4}{|c|}{$\begin{array}{l}\text { Contains information relevant to a single connection to a network. If multiple IP addresses } \\
\text { map to the same MAC address, each ai:connection SHALL represent a single MAC } \\
\text { address-IP address pair. }\end{array}$} \\
\hline \multirow{4}{*}{ Properties } & Name & Type & Count & Definition \\
\hline & $\begin{array}{l}\text { ip- } \\
\text { address }\end{array}$ & $\begin{array}{l}\text { literal - } \\
\text { token }\end{array}$ & $0-1$ & $\begin{array}{l}\text { The IP address for the connection. } \\
\text { IPv4 Regex: }([0-9]|[1-9][0-9]| 1([0-9][0-9]) \mid 2([0-4][0- \\
9] \mid 5[0-5])) \backslash .([0-9]|[1-9][0-9]| 1([0-9][0-9]) \mid 2([0-4][0- \\
9] \mid 5[0-5])) .([0-9]|[1-9][0-9]| 1([0-9][0-9]) \mid 2([0-4][0- \\
9] \mid 5[0-5])) \backslash .([0-9]|[1-9][0-9]| 1([0-9][0-9]) \mid 2([0-4][0- \\
9] \mid 5[0-5])) \\
\text { IPv6 Regex: }([0-9 a-f A-F]\{1,4\}:)\{7\}[0-9 a-f A-F]\{1,4\}\end{array}$ \\
\hline & $\begin{array}{l}\text { mac- } \\
\text { address }\end{array}$ & $\begin{array}{l}\text { literal - } \\
\text { ai:mac- } \\
\text { address-type }\end{array}$ & $0-1$ & $\begin{array}{l}\text { The Media Access Control address for the network } \\
\text { interface. } \\
\text { Regex: }([0-9 a-f A-F]\{2\}:)\{5\}[0-9 a-f A-F]\{2\}\end{array}$ \\
\hline & url & $\begin{array}{l}\text { literal - } \\
\text { URL }\end{array}$ & $0-n$ & $\begin{array}{l}\text { A Universal Resource Locator address for the network } \\
\text { interface. }\end{array}$ \\
\hline
\end{tabular}




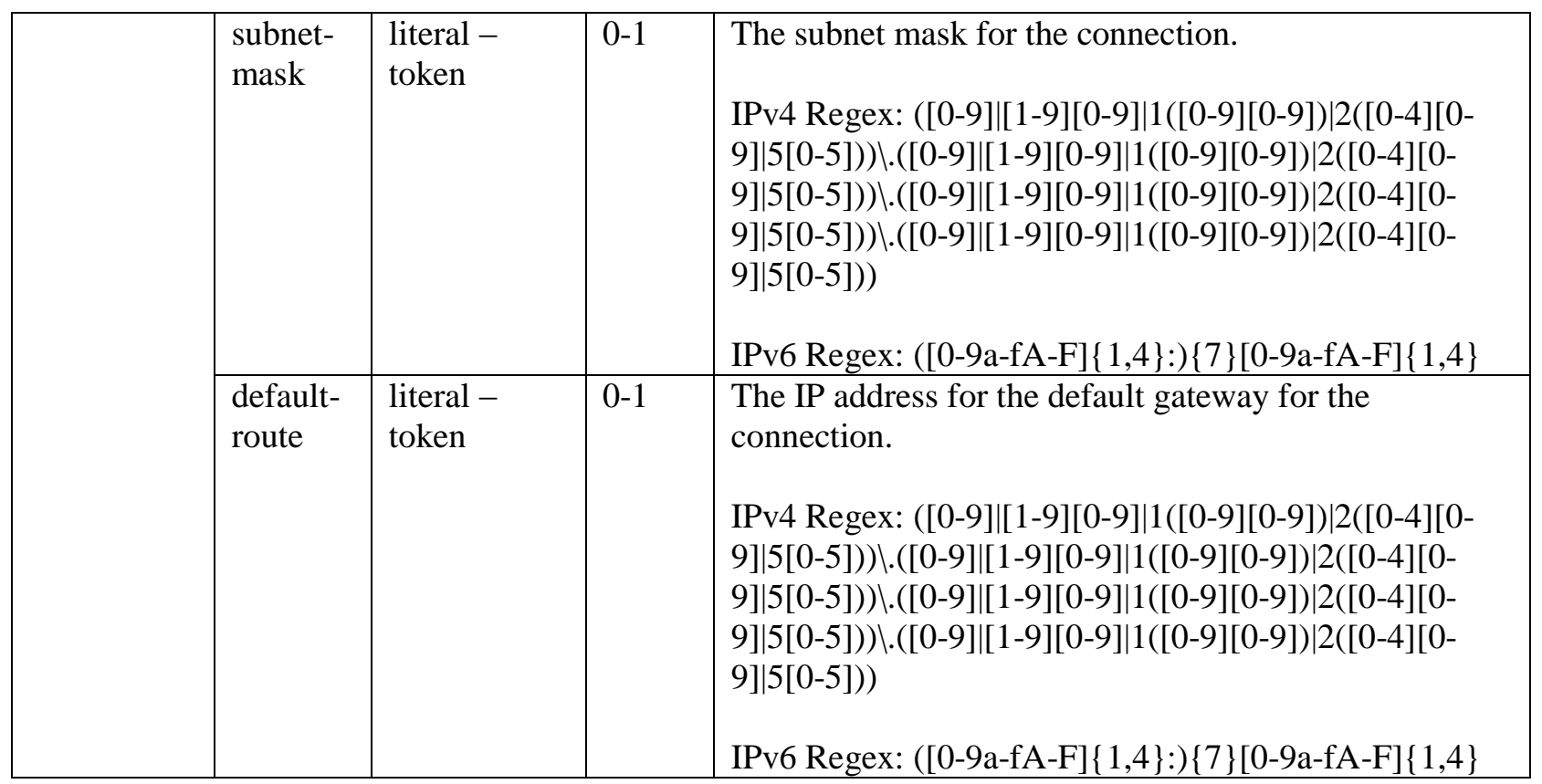

Table 6-17: Element - ai:locations

\begin{tabular}{|l|l|l|l|l|}
\hline \multicolumn{3}{|l|}{ Element Name: ai:locations } \\
\hline Definition & Contains a geographic coordinate system point. \\
\hline Properties & Name & Type & Count & Definition \\
\cline { 2 - 5 } & location & $\begin{array}{l}\text { element - one of: } \\
\text { location-point, } \\
\text { location-region, } \\
\text { location-address } \\
\text { (type } \\
\text { xal:AddressDetails) }\end{array}$ & $1-n$ & $\begin{array}{l}\text { ai:location is an abstract element that is the root } \\
\text { of the substitution group for the elements listed } \\
\text { in the type field. Use one of those to describe } \\
\text { the location of the asset. xal:AddressDetails is } \\
\text { defined in [xAL]. }\end{array}$ \\
\end{tabular}

Table 6-18: Element - ai:location-point

\begin{tabular}{|l|l|l|l|l|}
\hline \multicolumn{2}{|l|}{ Element Name: ai:location-point } \\
\hline Definition & Contains a geographic coordinate system point. \\
\hline Properties & Name & Type & Count & Definition \\
\cline { 2 - 5 } & latitude & $\begin{array}{l}\text { literal }- \\
\text { number }\end{array}$ & 1 & $\begin{array}{l}\text { The latitude of the point represented as a number between } \\
-90 \text { and } 90.90=90^{\circ} \mathrm{N},-90=90^{\circ} \mathrm{S} . \\
\text { Value constraint: }-90<=\mathrm{x}<=90\end{array}$ \\
\cline { 2 - 6 } & longitude & $\begin{array}{l}\text { literal }- \\
\text { number }\end{array}$ & 1 & $\begin{array}{l}\text { The longitude of the point represented as a number } \\
\text { between }-180 \text { and } 180.180=180^{\circ} \mathrm{E},-180=180^{\circ} \mathrm{W} . \\
\text { Value constraint: }-180<\mathrm{x}<=180\end{array}$ \\
\cline { 2 - 6 } & elevation & $\begin{array}{l}\text { literal }- \\
\text { number }\end{array}$ & $0-1$ & $\begin{array}{l}\text { The elevation of the point represented in meters above sea } \\
\text { level. A negative number would indicate below sea level. }\end{array}$ \\
\cline { 2 - 5 } & radius & $\begin{array}{l}\text { literal }- \\
\text { number }\end{array}$ & $0-1$ & $\begin{array}{l}\text { The radius of a horizontal circle centered on the point } \\
\text { within which the asset resides. } \\
\text { Value constraint: } \mathrm{x}>=0\end{array}$ \\
\hline
\end{tabular}


Table 6-19: Element - ai:location-region

\begin{tabular}{|l|l|l|l|l|}
\hline Element Name: ai:location-region \\
\hline Definition & Contains region information. \\
\hline \multirow{2}{*}{ Properties } & Name & Type & Count & Definition \\
\cline { 2 - 5 } & region-name & literal - normalizedString & 1 & The name of the region. \\
\hline
\end{tabular}

Table 6-20: Element - ai:ip-net-range

\begin{tabular}{|l|l|l|l|l|}
\hline Element Name: ai:ip-net-range \\
\hline Definition & \multicolumn{4}{|l|}{ Contains a start and end IP address to create a range. } \\
\hline Properties & Name & Type & Count & Definition \\
\cline { 2 - 5 } & ip-net-range-start & element - ai:ip-address & 1 & The start IP address of the range \\
\cline { 2 - 5 } & ip-net-range-end & element - ai:ip-address & 1 & The end IP address of the range \\
\hline
\end{tabular}

Table 6-21: Element - ai:ip-address

\begin{tabular}{|l|l|l|l|l|}
\hline \multicolumn{2}{|l|}{ Element Name: ai:ip-address } \\
\hline Definition & Contains an IP address. \\
\hline Properties & Name & Type & Count & Definition \\
\cline { 2 - 5 } & ip-v4 & $\begin{array}{l}\text { literal }- \\
\text { token }\end{array}$ & $0-1$ & An IP v4 address. \\
& & & Regex: $([0-9]|[1-9][0-9]| 1([0-9][0-9]) \mid 2([0-4][0-9] \mid 5[0-$ \\
& & & $5])) \backslash .([0-9]|[1-9][0-9]| 1([0-9][0-9]) \mid 2([0-4][0-9] \mid 5[0-$ \\
& & & $5])) \backslash .([0-9]|[1-9][0-9]| 1([0-9][0-9]) \mid 2([0-4][0-9] \mid 5[0-$ \\
& & & $5])) \backslash .([0-9]|[1-9][0-9]| 1([0-9][0-9]) \mid 2([0-4][0-9] \mid 5[0-5]))$ \\
\cline { 3 - 6 } & ip-v6 & literal - & $0-1$ & An IP v6 address. \\
& & token & & Regex: $([0-9 a-f A-F]\{1,4\}:)\{7\}[0-9 a-f A-F]\{1,4\}$ \\
& & &
\end{tabular}

Table 6-22: Element - ai:port-range

\begin{tabular}{|l|l|l|l|l|}
\hline Element Name: ai:port-range \\
\hline Definition & Contains a start and end port number to create a range. \\
\hline Properties & Name & Type & Count & Definition \\
\cline { 2 - 5 } & lower-bound & $\begin{array}{l}\text { literal }- \\
\text { token }\end{array}$ & 1 & $\begin{array}{l}\text { The lower bound (inclusive) of the range of ports. } \\
\text { Restricted to } 0<=\mathrm{x}<=65535\end{array}$ \\
\cline { 2 - 5 } & upper-bound & $\begin{array}{l}\text { literal }- \\
\text { token }\end{array}$ & 1 & $\begin{array}{l}\text { The lower bound (inclusive) of the range of ports. } \\
\text { Restricted to } 0<=\mathrm{x}<=65535 . \text { MUST be greater } \\
\text { than lower-bound. }\end{array}$ \\
\hline
\end{tabular}


Table 6-23: Element - ai:host

\begin{tabular}{|l|l|l|l|l|}
\hline Element Name: ai:host \\
\hline Definition & Holds a fully-qualified domain name or an IP address \\
\hline Properties & Name & Type & Count & Definition \\
\cline { 2 - 5 } & fqdn & literal - token & $\begin{array}{l}1 \\
\text { (either } \\
\text { but not } \\
\text { both) }\end{array}$ & $\begin{array}{l}\text { The fully-qualified domain name of the host. } \\
\text { One of fqdn or ip-address must be specified }\end{array}$ \\
\cline { 2 - 4 } & ip-address & $\begin{array}{l}\text { The IP address of the host. One of fqdn or ip- } \\
\text { eddress must be specified. }\end{array}$ \\
address
\end{tabular}

Table 6-24: Element - ai:cpe

Element Name: ai:cpe

Definition 1 A CPE 2.2 URI [CPE22] or CPE 2.3 formatted string [CPE23].

\subsection{Relating Assets to Other Assets}

While the assets modeled in Section 6.2, and their related elements, capture the literal values helpful for identifying the respective assets, it is often useful or necessary to define one or more relationships between assets. Those relationships can give additional context to the identifying algorithm in the implementing tool.

The Asset Identification data model allows for explicit relationships to be defined between an asset and one or more other assets. Each relationship is defined as \{subject\} \{predicate \{object\}, where \{subject is the asset from which the relationship begins, \{predicate is the relationship type being established, and \{object\} is one or more other assets. The predicate MUST be a qualified name that refers to a term in a controlled vocabulary. Section 6.4.1 documents the data model to represent assets along with relationships. Section 6.4.2 defines terms in a controlled vocabulary for Asset Identification.

\subsubsection{Relationship Data Model}

Asset Identification defines two elements that can be leveraged by specifications desiring to represent Asset Identification information. The first element, ai:asset-related, SHOULD be leveraged when the implementing specification desires to identify a single asset while demonstrating relationships between that asset and other assets. The second element, ai:assets, SHOULD be leveraged when the implementing specification desires to identify multiple assets while documenting the relationships between those assets and other assets. The two elements are documented in the following tables. 
Table 6-25: Element - ai:asset-related

\begin{tabular}{|c|c|c|c|c|}
\hline \multicolumn{5}{|c|}{ Element Name: ai:asset-related } \\
\hline Definition & \multicolumn{4}{|c|}{$\begin{array}{l}\text { Identifies a single asset while capturing the relationships between that asset and other } \\
\text { assets. }\end{array}$} \\
\hline \multirow{4}{*}{ Properties } & Name & Type & Count & Definition \\
\hline & asset-ref & literal - NCName & 1 & $\begin{array}{l}\text { Contains the ID value of an ai:asset found on } \\
\text { this ai:asset-related element. The asset } \\
\text { referenced from this property is the primary } \\
\text { asset of this element and SHALL be } \\
\text { understood to be the asset being identified by } \\
\text { this ai:asset-related element. }\end{array}$ \\
\hline & relationships & $\begin{array}{l}\text { element - } \\
\text { core:relationships }\end{array}$ & $0-1$ & $\begin{array}{l}\text { Contains the relationships between assets } \\
\text { identified in this element. }\end{array}$ \\
\hline & asset & element - ai:asset & $1-n$ & $\begin{array}{l}\text { The assets captured in this element. This } \\
\text { includes at minimum the primary asset } \\
\text { referenced in asset-ref, as well as any } \\
\text { additional assets that the primary asset is } \\
\text { related to through a relationship. }\end{array}$ \\
\hline
\end{tabular}

Table 6-26: Element - ai:assets

\begin{tabular}{|l|l|l|l|l|}
\hline \multicolumn{3}{|l|}{ Element Name: ai:assets } \\
\hline Definition & Identifies multiple assets as well as the relationships between the assets. \\
\hline Properties & Name & Type & Count & Definition \\
\cline { 2 - 5 } & relationships & $\begin{array}{l}\text { element - } \\
\text { core:relationships }\end{array}$ & $0-1$ & $\begin{array}{l}\text { Contains the relationships between assets } \\
\text { identified in this element. }\end{array}$ \\
\cline { 2 - 5 } & asset & element - ai:asset & $1-n$ & The assets captured in this element. \\
\hline
\end{tabular}

Table 6-27: Element - core:relationships

\begin{tabular}{|l|l|l|l|l|}
\hline Element Name: core:relationships \\
\hline Definition & \multicolumn{3}{|l|}{$\begin{array}{l}\text { Contains a collection of relationships between the report content and assets, report } \\
\text { requests, and other reports. }\end{array}$} \\
\hline Properties & Name & Type & Count & Definition \\
\cline { 2 - 4 } & relationship & $\begin{array}{l}\text { element }- \\
\text { core:relationship }\end{array}$ & $1-n$ & $\begin{array}{l}\text { Contains a relationship between the subject and } \\
\text { object(s) assets. }\end{array}$ \\
\hline
\end{tabular}


Table 6-28: Element - core:relationship

\begin{tabular}{|c|c|c|c|c|}
\hline \multicolumn{5}{|c|}{ Element Name: core:relationship } \\
\hline \multirow{2}{*}{\begin{tabular}{|l|} 
Definition \\
Properties
\end{tabular}} & \multicolumn{4}{|c|}{ Contains a relationship between the subject and object(s) assets. } \\
\hline & Name & Type & Count & Definition \\
\hline & ref & $\begin{array}{l}\text { literal - } \\
\text { NCName }\end{array}$ & $1-\mathrm{n}$ & $\begin{array}{l}\text { This element MUST identify the object of this relationship } \\
\text { by specifying the ID of the asset. Depending on the type of } \\
\text { relationship being asserted, there may be additional } \\
\text { restrictions on which types of objects may be referenced, } \\
\text { but that will be documented with the vocabulary term. }\end{array}$ \\
\hline & type & $\begin{array}{l}\text { literal - } \\
\text { QName }\end{array}$ & 1 & $\begin{array}{l}\text { This element contains the type of relationship that is being } \\
\text { specified. The QName MUST refer to a term in a } \\
\text { controlled vocabulary. The controlled vocabulary is } \\
\text { identified by the namespace URI of the QName, and the } \\
\text { term in that controlled vocabulary is specified by the local } \\
\text { name of the QName. It is helpful, though not required, that } \\
\text { when the namespace URI and local name are concatenated, } \\
\text { the resulting URI is dereferenceable and points to a } \\
\text { location that defines the term. }\end{array}$ \\
\hline & scope & $\begin{array}{l}\text { literal - } \\
\text { token }\end{array}$ & $0-1$ & $\begin{array}{l}\text { Determines how to interpret multiple ref elements in a } \\
\text { relationship. If used, this element MUST contain the string } \\
\text { "inclusive" or "exclusive". When this element is not } \\
\text { provided, its default value is "inclusive". When "inclusive" } \\
\text { is specified, this relationship should be understood to exist } \\
\text { between the subject asset and the collection of objects } \\
\text { identified by the ref elements on this relationship. When } \\
\text { "exclusive" is specified, this relationship should be } \\
\text { understood to exist between the subject asset and each } \\
\text { object asset identified by the ref elements individually. }\end{array}$ \\
\hline & subject & $\begin{array}{l}\text { literal - } \\
\text { NCName }\end{array}$ & 1 & $\begin{array}{l}\text { The property MUST identify the subject of the relationship } \\
\text { by specifying the ID of the asset. Depending on the type of } \\
\text { relationship being asserted, there may be additional } \\
\text { restrictions on which type of asset may be referenced, but } \\
\text { that will be documented with the vocabulary term. }\end{array}$ \\
\hline
\end{tabular}

\subsubsection{Relationship Types}

Defined below are terms in a controlled vocabulary for Asset Identification. It is OPTIONAL that content producers use the terms defined below, but all Asset Identification compliant implementations MUST understand the terms defined in this section. Content producers SHOULD use these terms when possible.

All terms listed in Table 6-29 exist in the controlled vocabulary identified by http://scap.nist.gov/specifications/ai/vocabulary/relationships/1.0\#. The definition of each term can also be found at the URL created when concatenating the URL and the term together. The table MUST be interpreted as follows:

- The "Term" column indicates the local-name of the term being identified.

- The "Domain" column indicates the exhaustive set of subject types that may be referenced by a relationship of that type. A relationship of that type MUST reference a subject of the type indicated in "Domain" for that relationship. 
- The "Range" column indicates the exhaustive set of object types that may be referenced by a relationship of that type. A relationship of that type MUST reference an object of the type indicated in "Range" for that relationship.

- The "Description" column contains a prose description of the relationship type. This column may contain requirement words as indicated in [RFC 2119]. Those requirement words MUST be interpreted as described in [RFC 2119] for the relationship.

Table 6-29: Controlled Vocabulary Defined for Asset Identification

\begin{tabular}{|c|c|c|c|}
\hline Term & Domain & Range & Description \\
\hline hasTerminationDevice & ai:circuit & $\begin{array}{l}\text { ai:computing- } \\
\text { device }\end{array}$ & $\begin{array}{l}\text { The circuit is terminated by } \\
\text { the device. }\end{array}$ \\
\hline hasServiceProvider & ai:circuit & ai:organization & $\begin{array}{l}\text { The circuit is owner/operated } \\
\text { by the organization. }\end{array}$ \\
\hline hasNetworkTerminationPoint & ai:circuit & ai:network & $\begin{array}{l}\text { The circuit ends at the } \\
\text { network. }\end{array}$ \\
\hline servedBy & $\begin{array}{l}\text { ai:database, } \\
\text { ai:website }\end{array}$ & ai:service & $\begin{array}{l}\text { The database or website is } \\
\text { served up by the service. }\end{array}$ \\
\hline hasServiceProvider & ai:service & ai:software & $\begin{array}{l}\text { The service is provided by the } \\
\text { software. }\end{array}$ \\
\hline installedOnDevice & ai:software & $\begin{array}{l}\text { ai:computing- } \\
\text { device }\end{array}$ & $\begin{array}{l}\text { The software is installed on } \\
\text { the computing device. }\end{array}$ \\
\hline connectedToNetwork & ai:system & ai:network & $\begin{array}{l}\text { The system is connected to } \\
\text { the network. }\end{array}$ \\
\hline isOwnerOf & $\begin{array}{l}\text { ai:person, } \\
\text { ai:organization }\end{array}$ & ai:it-asset & $\begin{array}{l}\text { The person or organization } \\
\text { owns the IT asset. }\end{array}$ \\
\hline isAdministratorOf & ai:person & $\begin{array}{l}\text { ai:computing- } \\
\text { device, } \\
\text { ai:system }\end{array}$ & $\begin{array}{l}\text { The person is the system } \\
\text { administrator of the } \\
\text { computing device or system. }\end{array}$ \\
\hline partOf & ai:person & ai:organization & $\begin{array}{l}\text { The person is in some way a } \\
\text { part of the organization. }\end{array}$ \\
\hline connectedTo & $\begin{array}{l}\text { ai:computing- } \\
\text { device, } \\
\text { ai:system }\end{array}$ & ai:system & $\begin{array}{l}\text { The computing device or } \\
\text { system is connected to the } \\
\text { system. }\end{array}$ \\
\hline
\end{tabular}

Content producers that choose to use terms that are not listed in Table 6-29, or to use other terms in addition to those listed in Table 6-29, MAY do so while still remaining compliant to this specification. Content producers SHALL always use terms defined in a controlled vocabulary. The controlled vocabulary SHALL be identified using a URI. Concatenating the controlled vocabulary URI with a term in the vocabulary MAY create a dereferencable URI that points to a definition for that term. This is often accomplished by using an HTTP URL for the controlled vocabulary URI, and ending that URL in "\#” or "/". For instance, http://scap.nist.gov/specifications/ai/vocabulary/relationships/1.0\#installedOnDevice is a deferenceable link to the definition of "installedOnDevice". 


\subsection{Guidance for Incorporating Asset Identification Elements into Other Data Models}

The following guidance applies when incorporating the Asset Identification data model into other data models.

- If the target data model needs to include a list of assets and the associated relationships between the assets, then the ai:assets element SHOULD be included in the target data model. This will be the case when the target data model will make explicit references to assets in the asset list.

- If the target data model needs to include a single asset, but other assets are needed to help identify that asset, then the ai:asset-related element SHOULD be included in the target data model. The @ asset-ref attribute on ai:asset-related SHALL refer to the specific asset that is being identified.

- If the target data model needs to include only a single asset, and no relationships are needed to identify that asset, then the element defining the asset MAY be included in the target data model. While this is allowed, it is preferred that the ai:asset-related element be included instead. 


\section{Appendix A-Use Cases}

The following use cases describe some common asset management processes that rely on the ability to uniquely identify assets. The asset identification specification was developed primarily in order to support these use cases, although the specification may be useful for other processes or uses.

\section{A.1 Correlation of Sensed Data}

Sensor data is not limited to an automated process: user surveys, manually entered information, and other data may also be correlated using this Asset Identification specification. The data must be correlated both with other manually collected data and with data collected by automated sensors, in order to build a complete representation of all known data about an asset.

Consistent asset identification allows data to be correlated regardless of:

- Collection timeframe

- Data type (vulnerability scan vs. user survey)

- Manual or automated process

- Data format

In this case, the goal of asset identification is to provide as much identifying information as possible about an asset in order to ensure the greatest probability of matching asset data from several different sources. Constraining which data is provided merely reduces the possibility of a match.

\section{A.2 Federation of Asset Databases}

While many smaller organizations may only have a single asset database, larger organizations with many asset databases may wish to share information about assets among them. This includes:

- Peer to peer relationships, where asset data is replicated and fused between several asset databases

- Hierarchical relationships, where an asset database is aggregated from several lower-level databases into fewer higher-level databases

In both use cases, asset identification facilitates detection of duplicate asset representations, correlation of asset data across the databases, and direct queries for asset data among tools.

In this use case, asset databases may wish to use a smaller set of data, or even a single identifier, in order to properly federate the asset data. For example, use of the motherboard GUID or single synthetic ID, such as an asset tag, may be sufficient to allow asset databases to exchange information about assets.

\section{A.3 Directly Targeted Remediation Actions}

While assessment and sensor data may be collected from all assets in a particular organization environment without specifically identifying a particular asset identifier, remediation actions require a more granular identification process that directly targets the asset using identification data. This ensures that unintended side effects are avoided and the intended remediation action is able to be completed successfully. 
A single agent identifier or motherboard GUID allows those triggering remediation actions to specify exactly which assets should have the remediation applied and allows the tools to unambiguously identify those assets in the remediation control language.

\section{A.4 Management of Asset Data}

Outside of the collection of sensor data and federation of asset databases, asset data may be used in a variety of management processes. This includes both further processing of asset data, such as aggregation for the purposes of metrics collection, and display to an end user. Both of these uses require asset identification be present to ensure all systems are able to accurately represent the correct assets. For purposes of aggregation, for example, asset identification may be used to request detailed data about outliers from the sensors that collected the data. 


\section{Appendix B-Extending the Asset Identification Specification}

Although the core Asset Identification specification should satisfy most users, some organizations may find that there are weaknesses or missing elements in the specification. In these cases, the organization may extend the Asset Identification specification by extending the XML schema that defines the data model. These extensions should be published as an XML schema to ensure that both schema extensions and instance documents are valid.

\section{B.1 Additional Asset Types}

Some organizations may wish to identify assets that are not contained in the valid asset list as defined in Section 5.3. To do this, additional XML elements can be defined that extend (using the XSD extension mechanism) an appropriate asset type (best practices entail using the most specific asset type that captures the necessary elements). Additional identification fields can be defined in the schema and additional relationships can be defined by creating new relationship types in a non-core controlled vocabulary.

\section{B.2 Additional Literal Identifiers for Existing Asset Types}

Additional literal identifiers for existing asset types may be added by creating schema elements in the extended-information element. Although there is no technical restriction of these fields to literal identifiers (i.e. information that is used to identify the asset), placing information in an asset element that does not help identify the asset is counter to the purpose of this specification.

\section{B.3 Additional Relationships}

Organizations may also wish to identify existing or new asset types using relationships that are not defined in the core specification. This may be accomplished by defining and publishing a relationship vocabulary in a separate namespace than the core Asset Identification relationship vocabulary.

\section{B.4 Additional Properties on Existing Data Elements}

The XML schema also provides extension points on most XML elements to allow for tracking metadata about Asset Identification information, such as classification level, sensitivity, or other organizationspecific data. As long as Asset Identification elements are able to validate against the core schema and conform to the requirements of this specification, these extensions and the Asset Identification elements are valid. 


\section{Appendix C-Normative References}

The following documents are indispensible references for understanding the application of this specification.

[CPE22] The MITRE Corporation (MITRE) Common Platform Enumeration (CPE) Specification Version 2.2, March 2009. See: http://cpe.mitre.org

[CPE23] NIST Interagency Report 7695, Common Platform Enumeration: Naming Specification Version 2.3, April 2011. See: http://csrc.nist.gov/publications/PubsNISTIRs.html\#NIST-IR-7695

[ILSR] IANA Language Subtag Registry. See http://www.iana.org/assignments/language-subtag-registry

[RFC 2119] Internet Engineering Task Force (IETF) Request for Comment (RFC) 2119: Key words for use in RFCs to Indicate Requirement Levels, March 1997. See: http://www.ietf.org/rfc/rfc2119.txt

[RFC 2396] Internet Engineering Task Force (IETF) Request for Comment (RFC) 2396: Uniform Resource Identifiers (URI): Generic Syntax, August 1998. See: http://www.ietf.org/rfc/rfc2396.txt

[RFC 5646] Internet Engineering Task Force (IETF) Request for Comment (RFC) 5646: Tags for Identifying Languages, September 2009. See: http://www.ietf.org/rfc/rfc5646.txt

[xAL] Organization for the Advancement of Structured Information Standards (OASIS) Extensible Address Language (xAL) Version 2.0, 24 July 2002. See: http://www.oasisopen.org/committees/ciq/ciq.html\#6

[XML] W3C Recommendation Extensible Markup Language (XML) 1.0 (Fifth Edition), 26 November 2008. See: http://www.w3.org/TR/REC-xml/

[XML Schema] W3C Recommendation XML Schema, 28 October 2004. See: http://www.w3.org/XML/Schema.html

[xNL] Organization for the Advancement of Structured Information Standards (OASIS) Extensible Name Language (xNL) Version 2.0, 24 July 2002. See: http://www.oasis-open.org/committees/ciq/ciq.html\#5 